\title{
Does Arts Education have a Future in Australia Against Literacy and Numeracy?
}

\author{
Susanne Garvis, Griffith Universiy, Queensland, Australia \\ Donna Pendergast, Griffith University, Queensland, Australia
}

\begin{abstract}
Arts education is considered a compulsory part of the school curriculum in Queensland, Australia. Many generalist teachers throughout the state are responsible for its delivery to students. Yet the teaching that occurs in generalist classrooms appears to be dictated by policy reform. In 2007, the Australian government began a National Assessment Program for Literacy and Numeracy for years 3, 5, 7 and 9. In Queensland, teaching for literacy and numeracy was further influenced in schools by the commissioned Masters report (2009). Further testing for literacy, numeracy and science would be carried out in years 4, 6 and 8 within Queensland. The influence of these policy initiatives on the teaching of arts education in schools is unclear. While arts shares equal footing as a key learning area, its actual importance in schools may be substantially lower. This paper helps to provide a current snapshot of the influence of this government reform. In 2008, 201 beginning teachers responded to a questionnaire investigating their personal beliefs and values of teaching arts education compared to maths and English. This study reports on parts of those findings. Results suggest beginning teachers were persuaded to teach English and maths by their schools to improve test results. Subsequently, some beginning teachers suggested they changed their teaching styles of arts integration to more traditional models. Findings hold key messages for the future of arts education and integration in schools. If schools and governments value arts education, they need to provide greater support for the teaching of arts education alongside literacy and numeracy.
\end{abstract}

Keywords: Arts Eduction, Teacher Self-efficacy, Generalist Teachers

\section{Literature Review}

\section{Current Reform Initiatives}

$\mathrm{I}$

2008, THE Federal Government of Australia initiated the National Assessment Program for Literacy and Numeracy (NAPLAN), designed to test literacy levels across Years 3, 5, 7, and 9. Results from the testing are available to the public. In 2008, Queensland performed second last out of all the states in Australia (Ministerial Council on Education, Employment, Training and Youth Affairs [MCEETYA], 2008), sparking an initiative by the state government to increase literacy and numeracy across all schools through increased lesson time and practice of the tests.

In 2008, in response to Queensland's low literacy and numeracy test scores, the Queensland government commissioned the Masters Report (2009) to improve levels of performance and understanding in literacy, numeracy and science. Key recommendations from the report included (2009, p. viii): 
1. That all aspiring primary teachers be required to demonstrate through test performances, as a condition of registration, that they meet threshold levels of knowledge about the teaching of literacy, numeracy and science and have sound levels of content knowledge in these areas.

2. That the Queensland Government introduce a new structure and program of advanced professional learning in literacy, numeracy and science for primary school teachers.

3. That additional funding be made available for the advanced training and employment of a number of 'specialist' literacy, numeracy and science teachers to work in schools (and/or district offices) most in need of support.

4. That standard science tests be introduced at Years four, six, eight and ten for school use in identifying students who are not meeting yearlevel expectations and for monitoring student progress over time.

5. That the Queensland Government initiates an expert review of international best practice in school leadership development with a view to introducing a new structure and program of advanced professional learning for primary school leaders focused on effective strategies for driving improved school performances in literacy, numeracy and science.

Paralleling these reforms, the development of the national curriculum by ACARA has seen the release of The Shape of the Australian Curriculum (2009). ACARA's work in developing the Australian curriculum is guided by the 2008 Melbourne Declaration on Educational Goals for Young Australians. The first phase subjects were English, mathematics, science and history. Along with geography and languages, arts education is part of the second phase of curriculum development due for release in mid 2010. Interestingly, The Shape of the Australian Curriculum identifies ten general capabilities to be addressed in the Australian curriculum. They are: literacy, numeracy, ICT, thinking skills, creativity, self management, teamwork, intercultural understanding, ethical behaviour and social competence. This brief overview of the curriculum reforms underway point to a greater focus in schooling on literacy, numeracy and science as a direct consequence of these government initiatives. The impact of these initiatives on arts education within Queensland is currently unknown.

\section{The Middle Years of Schooling in Queensland}

Within this wider curriculum reform context, middle years education has also featured as an aspect of education that has received the attention of reformers in Queensland in recent times. In 2003 See the future: The middle phase of learning State School Action Plan (2003) was launched as a response to The Ministerial Advisory Committee for Educational Reform report The middle phase of learning (Education Queensland, 2003). The report adopts the concept of the middle phase, defining it as typically occurring across Years 49 and falling into two distinct stages (Education Queensland, 2003, p.4);

- The first stage signals the transition from the early foundation years. For many students this is a time of expanding curiosity and eager exploration of a broader and deeper range of learning experiences. For others, the challenges are daunting, their interest wanes and progress slows.

- The second stage is characterised by the physical, social, emotional and intellectual development of early adolescence. Once again, there is considerable diversity in how and 
when students move through this stage and what the impact is on their attitude to and success in learning. It is essential in this stage to maintain students' interest and motivation and provide opportunities for them to "catch up" and make fresh starts when progress slows if they are to be ready for the senior phase of learning.

By defining each stage, the report clarifies the expectations of middle years school reform in each Queensland state school, requiring the alignment of curriculum, pedagogy and assessment to bring greater consistency and rigor to the middle years (Pendergast, 2007). It represents Education Queensland's commitment to a renewed focus on the Middle Phase of Learning to ensure that every student in Years 4 to 9 (Education Queensland, 2003) engages in purposeful, intellectually challenging learning; is provided with opportunities to achieve success; is supported in their transition from year to year and from primary to secondary education; and interacts with teachers who are prepared to meet the distinctive and diverse needs of students during early adolescence. These goals also clarify the role of teachers in addressing the needs of the middle years student. Teachers are expected to deliver quality education that provides adolescents with focused and achieved learning. Moreover, it provides greater accountability of teachers in the middle years.

\section{The Importance of the Arts in the Middle Years of Schooling}

The inclusion of arts education in the curriculum is important for student development, increasing the social and intellectual knowledge and skills of students. It is especially important for middle years student engagement with the learning process, a time identified in the literature when students may disengage (MYSA, 2008; Pendergast, 2007). Research has found that arts integration adds great value to the learning experiences of students as it: increases multicultural understandings (Goldberg, 1997); deepens understandings of text (Cecil \& Lauritzen, 1994); increases selfesteem and confidence (Harland, Kinder \& Hartley, 1995); furthers comprehension of mathematical and scientific concepts (Goldberg, 1997); may be used as a valuable entry point for educating underachieving students (Arnold, 2001); and has a positive impact on reading and critical thinking skills (DuPont, 1992). Arts education has also been linked to improved student motivation with Mussoline (1993, p.83) concluding that:

Art can be a powerful motivational tool to those who are successful. It can provide the impetus to succeed in other areas of school work...Participating in an art activity is generally a joyful experience for a child, regardless of his academic achievement level...Peer group acceptance through art work builds self esteem in the child who feels accepted and important.

Arts education may act as a motivator for school attendance and retention. In an evaluation of schoolbased arts education programmes in Australian schools (Bryce et al., 2004), students from Indigenous communities engaged in arts programmes had improved attendance at school. Similarly, in an American study investigating the impact of arts education on dropout rates, 22 out of the 36 atrisk students answered 'yes' when asked whether something about the arts had kept them at school (Barry, Taylor, \& Walls, 1990). This suggests that engagement with arts education also extends to increased student participation within school. 


\section{Focus of this Study}

This study focuses on the perceptions of the value and place of arts education compared to English and mathematics, as reported by beginning teachers. Beginning teachers are defined as within the first three years since graduating from a teaching degree. Beginning teachers were chosen as their beliefs are newly shaped by reform agendas.

\section{Methodology}

In 2008, two hundred and one beginning teachers in the middle years teachers completed a questionnaire, revealing their thoughts and experiences on the place and value of arts education. A snowball sampling technique was employed. This sampling procedure "refers to the process of accumulation as each located subject suggests others" (Babbie, 1999, p. 190) and was selected to address constraints of access, due to the wide regional location of the respondents, and the cost of engaging other sampling techniques (Mertens, 2005). Snowball sampling does not claim to result in a representative sample hence the findings are not generalisable to the entire population. However, given the participation of a large number of respondents, the findings provide a credible insight into the beliefs of beginning middle years arts teachers.

The data collection instrument included instructions and procedures to minimise response bias, and ethical clearance was obtained which confirmed to respondents that confidentiality was ensured. Safeguards were built into the instructions and the mode of administration of the questionnaire to minimise the potential motivational effects of selfassessment. Safeguards included: conducting the study without personal identification to reduce social evaluative concern; informing respondents that their responses remain confidential; identifying the questionnaire by code number, rather than name and explaining to the respondents the importance of their contribution to this research (Bandura, 2006). The instrument collected quantitative and qualitative data from selfreport questions. This paper reports on the qualitative findings, which are presented as text fragments.

The textual data was analysed using content analysis. Content analysis is a research technique that is employed to make "replicable and valid inferences from texts (or other meaningful matter) to the contexts of their use" (Krippendorff, 2004, p.18). An adapted version of Cavana, Delahaye \& Sekaran's (2003, p.171) 15 stages of content analysis (based within the constant comparative method) was used to identify key themes and meanings. This process allows newly identified themes to be compared with previously identified themes to ensure that the new theme adds more understanding about the phenomenon under investigation. Coding for manifest content (Wallen \& Fraenkel, 2001) was used, acknowledging what was directly written, as opposed to latent content which is implied.

FindingsContent analysis of the textual data from the beginning teachers in the middle years revealed two main themes in the data related to the value and place of the arts in school education:

- the importance of arts education; and

- negative perceptions of policy makers, schools, parents, and students towards the arts.

Each theme will be considered in turn. 


\section{Importance of Arts Education}

One strong theme emerging from the textual data was the importance of arts education. The notion of 'importance' was characterised in a range of ways. For instance, beginning middle year's teachers described the importance of arts education for the holistic development of the child, serving as an important means of ensuring a wellrounded education for all students. Respondents 54 and 53 capture the type of text expressing this view:

I have always believed that our role as educators is to produce well rounded people: arts must feature to this end (Respondent 54).

and

The arts are so important - it's an outlet for so many students and it needs to be used more. When it is used, the results speak for themselves! (Respondent 53).

This led to the view by some that arts education should be compulsory in the later years of school education, such as expressed by Respondent 30:

I believe arts education is an important and necessary part of any child's education. I believe it should be mandatory for all students to do the arts subjects till at least year 10 (Respondent 30).

Some beginning teachers stated that arts education is important because it serves as a vehicle for teaching and strengthening other subject areas, such as Respondent 2:

I think it acts as a vehicle to teach other subjects as well. It can really engage students. You also notice that some students who struggle with literacy and numeracy really excel in the arts (especially visual arts) so it is a great way to see the range of abilities and skills of the class (Respondent 2).

This led to comments about the importance of arts education as an integrative force, enabling curriculum to be better connected and hence of greater depth. This view is represented by the following text fragments:

Arts should be a cross curricula area and all students should be involved, it is just as important as other subjects. Arts students are able to extract more in depth knowledge and analysis than most other subject areas (Respondent 39). and I feel that a more integrated class - a curricular approach to middle school would be better than current traditional subject separation (Respondent 99).

The importance of arts education for learning beyond the classroom was also noted by a number of respondents, and captured in the following text:

Such skills are essential to give students, in a changing society a tool kit to play full part in their culture (Respondent 172).

Respondents consistently commented on the importance of arts education, as indicated in this summary, yet, there were concerns raised about the capacity of these middle years be- 
ginning teachers to deliver. The following text fragments capture the nature of this concern, particularly pointing to a lack of confidence, skills and knowledge to serve as effective arts educators:

The arts are fun and I realise very beneficial for student learning, however I have a lack of confidence to teach the arts. More in service would be good in some of these areas (Respondent 34).

and

It has significant relevance when incorporated effectively, however I am unsure how to do so (Respondent 18). and

I will try and implement the arts within the classroom, but my lack of skills and

knowledge limits me to how much I can do (Respondent 56).

\section{Perceived Opinions of Policy Makers, School, Parents and Students towards the Arts}

The second major theme identified in the text fragments was the negative perceptions of policy makers, schools, parents, and students towards the arts. Respondents suggested that the arts were undervalued in schools. They articulated what seems to be a common position that there is a greater focus placed on literacy and numeracy, with arts relegated to the margins in 'left over time', as a 'fillin' or as 'fun', as revealed in the following texts:

Ifeel like the arts is a KLA that is pushed aside due to expectations put on teachers in other areas like English, maths and behaviour management (Respondent 97).

and

There should be a set program instead of an "if there's time" activity (Respondent 60). and

I see art, in particular visual art, as a 'fill in' or reward activity. It doesn't seem to have the importance of literacy and numeracy. Parents never enquire about art and there is no benchmark for assessment (Respondent 82).

and

I think that the arts, especially in the junior school setting, but in middle/senior as well, tend to be overlooked in terms of importance (e.g. visual art is a 'fun' subject). While literacy and numeracy are of course extremely important I believe that the arts need to be given a bit more of a fair go. I think a lot of people often forget how important the tools that we learn and use in the arts classroom are, especially in relation to a great deal of tertiary study areas and eventually the workforce (Respondent 36).

Some respondents pointed to arts teachers themselves as contributors to this marginalised positioning, as articulated by Respondent 8

Many teachers allow students to develop this 'bludge' mentality by not valuing the arts themselves. It is a difficult battle to reform students' opinions. At my school, I do not believe the arts is/has been well valued which influences the students (Respondent 8). 
Some respondents pointed to the need for ongoing professional learning for generalist teachers, and for the inclusion of arts education specialists, such as Respondent 79:

Arts and technology are areas that I feel some teachers just do in an unstructured way. It is great kids get a chance to do it, but they also need to know why they are doing it. More in service or even specialists would be great in primary school (Respondent 79).

These comments highlight problems with the place and value of the arts in the school by teachers themselves. These views may permeate into other areas of the school community, creating a low level of overall collective efficacy of arts education.

\section{Discussion and Conclusion}

The two themes - the importance; and the negative perceptions of arts education that emerged from the data provide the basis for this discussion. Beginning middle year's generalist teachers in this research study consistently placed a high value on arts as an 'important' aspect of learning. Arts education was reportedly regarded as an important part of a holistic education for students, contributing to a well rounded education, particularly for middle year's students who are challenged by issues of alienation and disengagement from learning (MYSA, 2008). Even more profoundly reported was the value emerging from the integrative capacity of the arts, with it being noted as "a vehicle to teach other subjects well (Respondent 2) that "should be crosscurricula" leading to "more indepth knowledge and analysis" (Respondent 39). These respondent texts confirm the value of arts education as presented in the literature review, where arts is identified as "a powerful motivational tool" (Mussoline, 1993) which adds value to learning experiences, particularly when arts is used as an integrative tool. Some teachers questioned their ability to teach the arts, pointing to their own inadequate skills, techniques and pedagogical knowledge. This raises the question of adequate development of capacity for preservice teachers in the arts curriculum area. With an increasing focus on literacy, numeracy (and science) which is not yet reflected in preservice teacher education programs, it can be predicted that future graduates of teacher education programs are likely to have evenlessarts education preparation than those respondents in this study. It is therefore likely that this problem will be even further exacerbated in the future.

The second theme of negative perceptions of the value and place of arts education reportedly expressed by policy makers, parents and students seems to be the flip side of the coin of the first key theme - the importance of arts education. On the one hand the respondents have almost without exception pointed to the importance of arts education, expressing this in a range of ways. Yet, at the same time they reported that there was a common belief that literacy and numeracy were perceived to be more important for student learning and that accordingly arts education was marginalised in terms of time, student effort and perceived educational value. The effect of this marginalisation are not well understood, and it is likely that there will be an escalation in this effect as NAPLAN testing, the Masters Report recommendations and the National Curriculum have an increasing impact in classrooms around Queensland and Australia. There is no doubt that the place and value of arts education in the Queensland school curriculum has an uncertain future, and the findings from this study further highlight the need to develop a strategy to ensure that arts education is not relegated to the margins. This is particularly worrying in middle years classrooms, where challenges 
associated with alienation and disengagement reach a pivotal moment. Wright (2003, p. 221) proposes that "we must formulate a vision of how we want the future of arts education to look, and then work to make that vision a reality". Such a vision needs to be informed by research into the beliefs of preservice teachers, practising teachers and all of those responsible for school arts curriculum implementation.

This study has explored the values, beliefs and perceptions of beginning generalist teachers in the middle years towards the arts, compared to literacy and numeracy. Findings highlight the many tensions arts education experiences as greater policy focus is placed on accountability with literacy and numeracy. While teachers consider the arts important for middle year's students, they suggested that they were pushed by school agendas to focus on other subjects. If we are dedicated to providing a quality education in the middle years for all students, then policy makers, schools and teachers must reconsider the overall value of subjects and the importance of integrated approaches to learning.

\section{References}

Arnold, A. (2001). Towards a finer description of the connection between arts education and student achievement. Arts Education Policy Review, 102 (5), 25-6.

Apple, M.J. (1986). Teachers and Texts. London: Routledge and Kegan Paul.

Babbie, E. (1999) The basics of social research. Belmont, CA: Wadsworth.

Bandura, A. (2006). Adolescent Development from an Agentic Perspective. In F. Pajares \& T. Urdan (Eds.), Self-efficacy beliefs of Adolescents (pp.1-44). Connecticut: Information Age Publishing.

Barry, N., Taylor, J., \& Walls, K. (1990). The role of the fine and performing arts in high school dropout prevention. Tallahassee, Florida: Center for Music Research, Florida State University.

Bryce, J., Mendelvits, J., Beavis, A., McQueen, J., \& Adams, I. (2004). Evaluation of School-based Arts Education Programmes in Australian Schools. Canberra: ACER.

Cavana, R.Y., Delahaye, B.L., \& Sekaran, U. (2001). Applied business research: Qualitative and quantitative methods. Brisbane, Queensland: John Wiley and Sons.

Cecil, N.L., \& Lauritzen, P. (1994). Literacy and the arts for the integrated classroom. White Plains, NY: Longman.

DuPont. S. (1992). The effectiveness of creative drama as an instructional strategy to enhance the reading skills of fifth-grade remedial readers. Reading, Research and Instruction, 31(3), 4153.

Education Queensland. (2003). The Middle Phase of Learning State Action Plan. Queensland: Queensland Government.

Gay, L. R., Mills, G. E., \& Airasian, P. W. (2006). Educational research: Competencies for analysis and applications $\left(8^{\text {th }}\right.$ ed.). Upper Saddle River, N.J.: Merrill/Prentice Hall.

Goldberg, M. (1997). Arts and Learning. New York: Longman.

Harland, J., Kinder, K., \& Hartley, K. (1995). Arts in their View: a Study of Youth Participation in the Arts. Slough: NFER.

Krippendorff, K. (2004). Content analysis: An introduction to its methodology, 2nd ed. Beverly Hills, CA: Sage.

Masters, G. (2009). A Shared Challenge: Improving literacy, numeracy and science learning in Queensland Primary Schools. Victoria: ACER [online]. Retrieved online on 15 July 2009 from <http://education.qld.gov.au/mastersreview/pdfs/final-report-masters.pdf $>$

Mertens, D. M. (2005). Research and Evaluation in Education and Psychology. Integration diversity with quantitative, qualitative and mixed methods. (2nd Ed.). California: Sage Publications.

Middle Years of Schooling Association (MYSA) (2008). MYSA Position Paper: Middle Schooling: People, Practices and Places. Brisbane: MYSA. 
Ministerial Council on Employment, Education, Training and Youth Affairs. (2008). National Summary Report: Achievement in Reading, Writing, Language Conventions and Numeracy 2008 [Online]. Retrieved March 23, 2009 from <http://www.naplan.edu.au/naplan_2008_reporting/naplan_2008_reporting.html>

Mussoline, S.D. (1993). Art and Academic Achievement: a qualitative study of elementary school students. Dissertation, Miami, FL: Florida International University.

Pendergast, D. (2007). The MilGen and School Education. In N. Bahr \& D. Pendergast. (Eds.). The Millennial Adolescent. (pp. 268-314). Victoria: ACER Press.

Wallen, N., \& Fraenkel, J. (2001). Educational research: A guide to the process $\left(2^{\text {nd }} \mathrm{Ed}\right.$.). Mahwah, New Jersey: Lawrence Erlbaum.

Wright, S. (Ed.). (2003). Children, meaning-making and the arts. Australia: Pearson Education.

\section{About the Authors}

Susanne Garvis

The main focus of my work at Griffith Univrsiy has been the professional development of pre-service teachers. My research and teaching interests include teacher education and arts education, with a particular interest in music. I am currently undertaking a PhD study into the development of beginning teacher self-efficacy beliefs in arts and music education.

\section{Prof. Donna Pendergast}

Associate Professor Donna Pendergast has conducted a number of national research projects of significance including "Beyond the Middle", which investigated literacy and numeracy in middle schooling; and "Lifelong Learning and Middle Schooling". She has completed an evaluation of the Education Queensland Virtual Schooling Service and is often employed as a consultant to review school reform initiatives. Donna has several books published of relevance to contemporary teacher work, including Teaching the Middle Years; The Millennial Adolescent; and Groovy Chicks and Blokey Blokes. Donna is highly sought after as a speaker on the topic of the MilGen and teaching, and has completed several intergenerational studies in content areas. 